\title{
Analysis of Problems in Cost Management of Construction Companies in Henan Province
}

\author{
Shuying Wang, Jiapeng Zhang \\ Zhengzhou University, Henan, China \\ 654062842@qq.com
}

Keywords: Construction Company, Cost Management, Project Changes, Engineering Claim

\begin{abstract}
At present, with the development of the market economy and the regulation of the government's release policy, the competition in China's construction industry is getting fiercer and the development is getting more and more perfect. Based on the analysis and research on the existing problems of construction companies in Henan Province, this paper argues that each project needs to establish a cost management system in accordance with the principle of cost management of ordinary projects, and also needs to combine the characteristics of the construction projects established by large construction companies, clarify the task of total contract cost management of the project to determine the project cost management methods and ways to achieve the expected project cost management objectives.
\end{abstract}

\section{Introduction}

At this stage, with the development of market economy, the development of China's construction enterprise management model is more and more perfect. The construction industry is gradually becoming mature. Many large construction companies have started to mushroomed in Henan Province. With the constant establishment and development of construction companies, the cost management of construction companies in Henan Province has gradually become the focus of discussion this year. To date, the cost management issues for large construction companies are broadly divided into the following sections: First, it analyzes the impact of current government policies, market conditions and laws and regulations on project cost management, points out that such problems cannot be ignored objectively(Xiaodong Dong,2008); The second is to analyze and study the various stages around a general project from a project itself, to explore the advantages and disadvantages of project control, cost management and full control. It is found that the design stage and the construction stage are the two stages that have the greatest impact on the construction cost, material is one of the most influential factors (Huoxian Chen,2012); The third is to summarize and analyze human resources, and investigate the quality and skills of the current construction personnel. The demand for construction talents in the construction market is far greater than the supply, the workers' construction technology and the ability to solve problems cannot keep pace with the rapid development (Baoling Hou,2010); Fourthly, considering all the main units involved in the project, designers and construction units have different degrees of impact on different stages of the project (Qifu He,2012).

In this paper, large construction companies in Henan Province as the scope of the study, the use of data comparison, case analysis methods, the cost management of the problems in the investigation and analysis in order to better take measures to solve for the company to maximize benefits. First of all, it accurately defines the project cost management, analyzes and explains the status quo of project cost management in current construction companies in Henan Province, and analyzes the problems caused by the cost management of construction companies from the outside and inside again. Finally,Project for the case analysis and analysis of the previous cost management issues are summarized. 


\section{Theoretical basis}

The main content of the construction project, which is the project cost management, is to identify and control the project cost, which involves the project technical and economic activities and the operation and management of the project. It is a unique project management field. The goal of cost management is to comply with the development trend of the socialist market economy in accordance with the law of economic law and at the same time utilize the scientific advanced management methods to reasonably determine and effectively control the cost of the project (Xiaoli Li,1996).

The investment estimation phase of the project is an important part of the proposed project. The investment decision-making process can be divided into the project planning stage, the project proposal stage, the preliminary feasibility study stage, the detailed feasibility study stage, the assessment review stage, the design task stage. Table 1 shows the cost management in different stages.

Although the design fee only accounts for a small part (about 1\%) of the total investment in a project, the design phase basically determines the cost of the construction project in the future and has a significant impact on the total investment of the project and is often overlooked. At this stage, the form of cost and the objectives and methods of cost management are shown in the following figure, which shows that the cost control in the design phase is to control the preliminary design with the approved investment estimate, design the design budget in the preliminary design stage, and control the construction with the design outline figure design, construction drawings in the design stage construction budget. The design phase is the source control phase of cost management and is the most fundamental and important control. This results in a complete dynamic control of the estimated control budget and the estimated budget control budget, as shown in Table 2.

Table 1: The stage of investment estimation and its main contents.

\begin{tabular}{|c|c|}
\hline stage & Cost management content \\
\hline Project planning & $\begin{array}{c}\text { In accordance with the planning } \\
\text { requirements and content of the rough } \\
\text { estimate of the amount of investment } \\
\text { projects }\end{array}$ \\
\hline The project proposal & $\begin{array}{c}\text { Negate or determine whether the project } \\
\text { needs the next phase of work }\end{array}$ \\
\hline Preliminary feasibility study & $\begin{array}{c}\text { Whether to conduct a detailed feasibility } \\
\text { study }\end{array}$ \\
\hline Detailed feasibility study & $\begin{array}{c}\text { Decide whether the project investment, } \\
\text { cost and other costs are feasible }\end{array}$ \\
\hline Assessment review & $\begin{array}{c}\text { As the basis for the final decision of the } \\
\text { project }\end{array}$ \\
\hline Design task book & $\begin{array}{c}\text { Control initial design estimates and the } \\
\text { entire project cost ceiling }\end{array}$ \\
\hline
\end{tabular}

Table 2: Engineering design stage cost performance, cost management objectives and methods.

\begin{tabular}{|c|c|}
\hline project & Description \\
\hline Project cost form of expression & $\begin{array}{c}\text { Design estimates, construction } \\
\text { drawings budget }\end{array}$ \\
\hline $\begin{array}{c}\text { Project cost management } \\
\text { objectives }\end{array}$ & $\begin{array}{c}\text { Optimum economic and rational, } \\
\text { advanced technology design }\end{array}$ \\
\hline Project cost management methods & $\begin{array}{c}\text { Design competition, quota design, } \\
\text { standard design }\end{array}$ \\
\hline
\end{tabular}

Construction phase is the construction phase of the construction project, a project cost of $90 \%$ 
are used in the construction process, but also the most complex and most difficult to manage the stage. In addition to the other construction costs incurred during the construction period, a large amount of investment funds are continuously "materialized" through construction so as to eventually form a fixed asset to achieve project investment. Construction budget is the construction company needs to focus on the control of the content, including engineering construction measurement, engineering changes to determine the price, engineering claims control, cost management at this stage the purpose is to control the cost of the project construction, and the actual investment amount of not more than cost control target value.

(1)Construction measurement.

Engineering construction measurement is the key to cost management. Through the project management agencies to declare the construction company to complete the construction project quantity check and determine the number of construction companies have to pay the project vouchers.

(2)Determine the project to change the price. Changes often occur in the construction phase of a project. For example, due to the defects of investigation and design work, construction projects have to be changed in the construction process to increase or decrease the engineering changes that occur in the engineering quantities; the suspension due to changes in the natural environment, social causes, etc.duration of delays and so on.

(3)Control of engineering claims. Engineering claims occur from time to time in actual project construction. There are two elements that result from the construction: one party has losses and one party has no fault. In practical work, claims are the aspects that cost managers need to emphasize and strengthen management. It is also common for construction companies and contractors to contradict claims during construction, so claim control is also an important part of cost management during construction.

The completion of the project settlement truthfully reflect the price of construction projects, is a project cost management "terminal." The cost management at this stage is the final price of the contract, the real and reasonable determination of the settlement amount of the project. After the completion of the project is delivered and used, the construction company needs to conduct postproject evaluation, summarize the experience, analyze the defects and deficiencies of the project process management, analyze and compare the changes of project scope, progress and cost according to predetermined rules, Sorted into the computer for future reference.

Project cost management has now generally accepted for the construction industry, which runs through the construction project from start to finish, controlling the entire process of project construction. However, in terms of management, construction technology, professional awareness of construction personnel management personnel, environmental awareness, there are still many shortcomings and deficiencies in our country. The process of urbanization is accelerating while promoting a sustained, rapid and healthy construction industry in Henan Province (Lishuang Yin,2012).

\section{Henan construction company cost management problems}

Construction companies in a construction project from investment estimates to the completion and settlement of the entire process has been involved from the design units, construction units, construction companies themselves and many other aspects of the impact of these various factors will inevitably give the construction company cost management and bring great pressure and numerous difficulties. Large construction companies in Henan Province are representative and specific to the entire construction industry in Henan. Large construction companies undertake more projects than any other construction company. Therefore, there are a variety of problems in cost management. In general, from the characteristics of project cost management, the large amount of investment and the dynamics of the process are the main factors that affect the cost management. In the actual cost management, there are more or less problems and deficiencies in all aspects of the project from all aspects. After some investigation and study, the main problems are now grouped into several parts. 


\subsection{Process control is not strict, cost management is flawed}

(1) During the actual implementation of the project, managers are having difficulty in handling the issue of "three beings and one law of silence", namely, the unity of quotas, orderability, comprehensiveness and the static nature of the prices of materials, workers and machinery. When the managers deal with the bad characteristics of each branch, the unexpected situations encountered in the management work are easily handled improperly, resulting in the waste of construction funds, the insufficient utilization of materials, the serious waste of materials and equipments in the construction process, cost management difficult to carry out. In actual work, such phenomena also occur from time to time. Managers did not strictly carry out process control, such as artificial mechanical nesting phenomenon, backward construction technology, construction personnel not strong concept, resulting in high cost even over the construction budget.

(2) In the area of cost control, the "four counties" are severely separated. Estimates, estimates, budgets and final accounts cannot be effectively combined with each other. The "three super" phenomenon has been ubiquitous. The reason for the existence of the "three super" problems lies in the fact that construction projects have a longer construction period and more environmental, social and management variables. The unforeseen costs of extra-budgetary projects account for a large proportion of the construction costs. At the same time, the management staff is not strict enough in cost control. Some supervisors, management departments and specific operators of the project do not match the behaviors. The understanding of some issues is different, such as design changes, engineering changes, materials substitution, Hidden projects or the cost of on-site visa projects are unforeseen extra-budgetary costs, resulting in budget estimates over estimates, budget estimates over budget, budget overruns serious phenomenon, therefore, cost control is the cost management cannot be ignored.

\subsection{Engineering changes and claims management is not appropriate}

(1)Project changes

Through the investigation of the construction stage of the project, the project change is directly related to the "three super" phenomenon, and the construction changes related to the progress of the construction will inevitably lead to the increase of the construction cost. Meanwhile, the project alteration will result in the decrease of the productivity. Engineering changes occur for many reasons, and may come from different subjects, so there is a lot of problems and deficiencies in the management of construction companies in this area when engineering changes occur during the construction phase of a project: Some cost management personnel loosely manage the process, system, organization structure, methods and tactics of engineering change, the implementation is not complete and the method is simple; Improper management of the contract led to the engineering changes cannot be effectively controlled; construction site management is not standard; managers cannot reasonably control the amount of materials, materials cannot be reasonably determine the price; the same time, the construction company's engineering change committee monitoring is not enough. Construction companies should reduce the cost of engineering changes, reduce change delays, and get the maximum benefit from the company.

(2)Engineering Claim

In our country engineering claims can be regarded as a new discipline, is the weak link of many construction companies. Many construction companies in our country still have vague and even wrong understanding of the understanding and management of claims. Some construction company's cost management staff cannot reasonably and reasonably handle claims costs due to lack of knowledge and concept of claims so that the construction company cannot reasonably and legally control the construction cost and has not yet mastered the claims process management and management system, negotiation skills, management methods are also the problems of the current construction company engineering claims. At the same time, construction companies also lack experience in counterclaims and lack some relevant theory of knowledge.

\subsection{Inadequate internal management}

(1)Poor management awareness.

At present, the cost management of most large construction companies in Henan Province is not 
aware of the management of the project, and the emphasis on cost management is not enough, which makes it impossible to take effective and timely measures to make some non-procedural decisions. The internal management mode of construction companies does not provide the cost managers with the opportunity to learn new knowledge and skills. Managers themselves are seldom aware of the shortcomings of knowledge and technology updates on the project. Therefore, managers should not take reasonable and effective measures management method.

(2)Human resources are not perfect

According to rough statistics, currently there are more than 6,000 construction companies in Henan Province, employing more than 1.3 million people, including over 400 large-scale construction companies. This figure shows that there are quite a few people engaged in the construction industry. In fact, among those engaged in the construction industry, there are not many practitioners who have intensively studied or learned about the construction industry. Construction workers often lack awareness of cost management and lack some construction work experience, Do not have the relevant professional qualifications, resulting in the construction phase can not take a better technical level(Zengqiang Yang,2009).

\section{Case analysis}

\subsection{Case basic situation}

A real estate project in Henan Province was investigated during 2015. The following is the basic status of the project: The project is located in a city in the western suburbs of Zhengzhou City, Henan Province, which is under construction by a large construction company in Henan Province (hereinafter referred to as A Company), the project is also developed by the local enterprises in Henan to residential + end of the traditional real estate projects. Construction area of 700000 square, is a small and medium-sized building scale real estate. Events during the construction project are as follows:

(1)A company based on the geological data provided by the owners, geological survey conducted in May to report the groundwater level of 4.5 meters, accordingly, A company that the project does not require precipitation. After the project started in July, when digging a pit of $7 \mathrm{~m}$ deep, it encountered severe underground seepage and had to install a pumping system and started for 32 days. Company A claimed for this unforeseen additional cost.

(2)In January of the next year, due to the owners to modify the design and ordered Company A to stop working for a month, in which case Company A claims to the owner for overdue storage of materials or material prices.

\subsection{Analysis of the case of cost management problems}

A company in the case of two cases are related to the claim, the construction and settlement phase of the construction company to the owner in time for the final stage of the cost of construction, the claim will have to submit documents to the owners claim.

(1)A company claim to the owners does not hold. Because of the geological data, drilling was conducted in May, which means it was at the end of the dry season, while Company A's excavation took place during the rainy season. Company A should anticipate that there will be a higher water level. This risk is not unpredictable, so the claim does not hold.

(2)The claim was established because of a claim arising from a change of construction. However, Company A's claim is not comprehensive enough and its claimable costs are as follows:

Labor costs: For workers who cannot be dismissed, compensation workers nest fee; Subcontracting fee: due to the suspension of construction subcontractor claims to the general contractor fees; Site management fee: Due to a total shutdown, you can claim the resulting increase in site management fees;

Insurance premiums: one month's claim for insurance; Warranty fee: one month warranty claim fee can be claimed; Interest: Interest expenses that can be claimed for a one-month extension of claim;

Headquarters management fee: if only partially suspended, claim management overhead may not be established. Due to a total suspension of work, there is an additional overhead management fee 
claim extension.

\subsection{Case Conclusion}

The case of some major construction companies in the engineering changes and claims on some of the errors or deficiencies in the handling of the project led to the cost of improper management. Case has a certain representation, which is what Henan Province, large construction companies often appear in the construction project problems and deficiencies.

With respect to engineering changes and engineering claims, construction companies tend to easily overlook the lack of training and guidance of relevant theories and policy documents, leaving engineering changes and engineering claims without the proper treatment and resolution. In addition, managers sometimes devote little effort to devote more time and energy during the bidding process or completion of the project, but did not pay enough attention to the management of this complicated period during the construction period. As early as the construction period, there were similar cases In fact, there are a lot of practical problems in the management, the management did not take the most correct and most reasonable measures and ways to solve(Kun Yao,2011), which is the construction company cost management practical problems.

\section{Countermeasures and Suggestions}

\subsection{Cost management of the effective way}

Through the research on the problems of cost management of large construction companies in Henan Province, construction companies should take effective solutions to these problems. In view of the status quo and problems raised in the preceding paragraphs, the following several effective measures are proposed:

Construction projects take the whole process of dynamic management of the construction cost form; Strengthen the design and management of construction organization and implement the dynamic control over construction cost; Strengthen engineering change and claim control, implement contract management in all aspects and strengthen construction supervision; Construction companies establish and improve the management mechanism to strengthen legal publicity and construction of ways to improve audit approach Earnestly audit the final accounts to strengthen the supervision of intermediaries.

\subsection{Strengthen the application of BIM}

Building Information Modeling (BIM) is a direct expression of digital technology in the construction industry and is a landmark change in the construction industry. After some superficial research on the problems of cost management of large construction companies in Henan Province, if more and more construction companies combine BIM-related knowledge and technology in the construction phase, the cost management will be much easier and easier. Construction The process will also be less difficult and more complicated.

The widespread use of BIM is an inevitable development trend of the current construction industry, playing a significant positive role and impact on cost management, with far-reaching prospects for development. Cost management of construction companies can solve the prevailing problems in the current industry, change the status of construction cost management, and at the same time, it can effectively promote the level of social productivity in the industry. Project cost must have a strict basis, but not indiscriminate, wanton offer. At present, Henan and even China's entire construction industry are generally fake and false reports, blindly lowering the project cost situation, these acts can easily disrupt the construction industry's current market economic order, resulting in the waste of resources. Therefore, the implementation of project cost management can regulate the market order of the construction industry, save money and avoid a lot of waste of resources, but also enable construction enterprises to operate in a sound economic order and improve the social efficiency of the entire industry.

\section{References}

[1] Huoxian Chen, 2012. Main Factors Affecting Project Cost and Effective Control, Science and 
Technology Wind. (11), pp. 270-270.

[2] Xiaodong Dong, 2008.The main factors affecting project cost and reasonable control methods, Building Economy.29 (9), pp.117-119.

[3] Qifu He,2012.Project Cost Management of Construction Company ,Assets \s \& \sfinances in Administration $\backslash \mathrm{s} \& \backslash$ sinstitution.(4),pp.132-133.

[4] Baoling Hou, 2010.Engineering cost management hereby and the status of my research, Science and Technology Information. (35), pp. 175-175.

[5] Xiaoli Li, 1996.My view on the management of fixed assets in research institutions. Journal of Harbin University of Commerce. (6).

[6] Zengqiang Yang, 2009.On the design stage of project cost management problems and countermeasures, Petroleum Engineering Construction.35 (16), pp.245-246.

[7] Kun Yao,2011. Research on the Necessity of the Whole Process Control of Project Cost Management, Management Management. (9), pp.105-105.

[8] Li-shuang Yin, 2012.Study on Improvement of Engineering Cost Management of Donghui Construction Company,Jilin University, 2012 (3). 